\title{
Postoperative recovery from the perspective of day surgery patients: A phenomenographic study
}

Katarina Berg, Kristofer Franzén Årestedt and Karin Kjellgren

Linköping University Post Print

\section{Tweet}

N.B.: When citing this work, cite the original article.

Original Publication:

Katarina Berg, Kristofer Franzén Årestedt and Karin Kjellgren, Postoperative recovery from the perspective of day surgery patients: A phenomenographic study, 2013, International Journal of Nursing Studies, (50), 12, 1630-1638.

http://dx.doi.org/10.1016/j.ijnurstu.2013.05.002

Copyright: Elsevier

http://www.elsevier.com/

Postprint available at: Linköping University Electronic Press

http://urn.kb.se/resolve?urn=urn:nbn:se:liu:diva-85026 


\section{Abstract}

Background: Today, many patients undergo surgical procedures in a day surgery setting. The shift from inpatient care to care at the patient's own home following discharge places various demands on patients and their families during the recovery process. There is a need for knowledge of how the postoperative recovery process is perceived, as research indicates a lack of support for patients managing recovery at home.

Objective: To explore day surgery patients' different perceptions of postoperative recovery. Design: A qualitative design with a phenomenographic approach was used.

Methods and settings: Semi-structured interviews with 31 patients undergoing an orthopaedic, general or urologic day surgical procedure were carried out face to face at the patients' homes, 11-37 days post-discharge. Patients were recruited from two day surgery settings: one private unit and one unit associated with a local county hospital.

Results: The patients perceived postoperative recovery as comprising internal and external prerequisites and implying changes in ordinary life with varying levels of support. The effective production at the day surgery unit was perceived as having an impact on patients' prerequisites for recovery. The results are elucidated in three descriptive categories: 'Conditions for recovery at home', 'The rollback to ordinary life' and 'Being a cog in a flow of care'.

Conclusions: The postoperative phase seems to be a weak link in day surgery care. From the patients' perspective, postoperative recovery following day surgery implies extensive responsibility at home. Patients need knowledge and understanding concerning what constitutes the normal range in recovery and how to manage self-care following their specific surgical procedure.

Key words: ambulatory surgical procedures, nursing, phenomenography, postoperative period, qualitative research, self-care 
What is already known about the topic?

- Numerous patients undergo day surgery, and the number is expected to increase in coming years.

- Postoperative recovery is influenced by individual and external factors.

- Day surgery is characterized by high demands on productivity and cost-effectiveness.

\section{What does this paper add?}

- More attention has to be paid on the postoperative phase of day surgery.

- Day surgery patients want and need to be better informed concerning what is regarded as a normal postoperative recovery process in relation to the surgical procedure they have undergone.

- The need of support for self-care is related to the specific surgical procedure and to the individual patient's prerequisites taking care of themselves. 


\section{Introduction}

Day surgery is widely applied in many countries' health care systems and often represents more than $50 \%$ of all surgery (Toftgaard, 2009). This study has been carried out in Sweden, where approximately $80 \%$ of elective surgery is performed as a day surgical procedure (Toftgaard, 2012). Several surgeries have been transferred from in-hospital to day surgical procedures (e.g. laparoscopic cholecystectomy, anterior cruciate ligament repair, hernia repair in the elderly, shoulder surgery as well as minor procedures for gynaecological prolapse and urine incontinency) (Segerdahl et al., 2007). Day surgery implies admittance, surgery and discharge without an overnight stay (Toftgaard and Parmentier, 2006), and minimal disruption of ordinary life (Mottram, 2010). Most patients appreciate the possible choice of day surgery (Lemos et al., 2009, Martin et al., 2010, Rhodes et al., 2006, Tysome and Padgham, 2006), and it is perceived as less risky (risks concerning anaesthesia, loss of personal autonomy and separation from one's family) than if undergoing an in-hospital surgical procedure (Mottram, 2012). On the other hand, the day surgery patient does not have the advantage of postoperative surveillance by professionals following discharge (Kleinbeck, 2000). Instead, postoperative care is transferred to the patient and the family, who have to manage the recovery by themselves, which might raise feelings of insecurity at home (Boughton and Halliday, 2009, Gilmartin, 2007, Mitchell, 2003, Mottram, 2011). A lack of professional support (Mottram, 2011), information and insufficient preparation for self-care at home (Boughton and Halliday, 2009), inadequate communication between day surgery and community care (Mitchell, 2003) and overoptimistic expectations concerning recovery (Gilmartin, 2007, Mottram, 2010) may contribute to this insecurity. However, from a personal and social perspective the transfer of responsibility for postoperative care to the home environment is mostly accepted by patients and their families (Majholm et al., 2012). 
The postoperative course is influenced by many factors, including patient characteristics, type of surgery and anaesthesia, and social factors (Bettelli, 2009). Postoperative symptoms can be troublesome, and are a common reason for unplanned contact with health care following discharge (Mattila et al., 2005). Symptoms also cause a delay in patients' return to daily life functions (Rosén et al., 2009). Reviews report pain and nausea as the most common postoperative symptoms, followed by drowsiness, tiredness, fatigue and dizziness (Rosén et al., 2009, Schnaider and Chung, 2006, Wu et al., 2002). Patients also have to deal with psychological issues post-discharge, for instance mood swings and anxiety. Also, a changed body image and appearance due to swelling and discoloration of the surgery site might be bothersome for some patients (Demir et al., 2008, Gilmartin, 2007). Many day surgery patients expect recovery to be fast (Mottram, 2010), with no (or only limited) effects on role functions. However, non-resumed role functions in family and social life are not unusual (Horvath, 2003, Mottram, 2010, Mottram, 2011). Nursing in day surgery has to adapt to an environment characterized by productivity and cost-effectiveness. To ensure a safe and efficient throughput, nursing often focuses on physiological measurements. However, to attain a patient-centred approach and to enable patients to successfully manage their recovery, psychosocial aspects have to be taken into account (Demir et al., 2008, Mitchell, 2010).

Day surgery has developed very rapidly in recent decades, and is today a 'streamlined' process offering excellent physical care. Yet, when it comes to the time following surgery, research indicates a lack of support for patients' management of their postoperative recovery at home (Mottram, 2011). To improve the care, a better understanding of variations in patients' needs after surgery would be valuable. The aim of this study was therefore to explore day surgery patients' different experiences of postoperative recovery. 


\section{Method}

Design

A qualitative design with a phenomenographic approach was used. Phenomenography seeks an understanding of people's different ways of experiencing phenomena in their surrounding world. From a phenomenographic perspective, this means a description of people's conceptions of the reality and context in which they are participating (Marton, 1981). The results in a phenomenographic study comprise a set of descriptive categories which are qualitatively different from each other (Dahlgren and Fallsberg, 1991). In this study, this implies descriptions of various ways people conceive of postoperative recovery following day surgery, ordered in different categories. This focus on variations is a fundamental difference from phenomenologic research, which instead examines the essence of the phenomenon in question (Sjöström and Dahlgren, 2002). Performing a phenomenographic analysis means that the data are handled as one set to achieve descriptions related to the group of respondents rather than separate individuals (Marton and Booth, 1997).

\section{Participants}

The sampling was strategic, and patients were selected from two different day surgery units: one private, standalone unit and one unit associated with a local county hospital. The inclusion criteria were: aged 18 years and over and discharged without an overnight stay. The exclusion criteria were: acute or re-operation, poor Swedish language skills or reduced ability to communicate, for instance impaired hearing or cognitive dysfunction. Patients who met the inclusion criteria were chosen by the first author, and to obtain variation in the sample patients were chosen regarding surgical procedure, age and gender. No women were scheduled for gynaecological surgery at the units during the period of data collection, resulting in fewer women being available. A study-specific nurse affiliated with the surgery 
unit approached selected patients at admission and gave verbal and written information about the study. A total of 37 patients were invited to participate, and those who consented to participate were contacted by telephone by the first author within ten days post-discharge. On this occasion the information was repeated, and time and place for the interview were determined. However, four patients were not able to be contacted and two had been hospitalized. Of the 31 participants who were ultimately included, 23 were men and eight were women, with ages ranging from 18 to 80 years. Orthopaedic, general and urologic surgeries were represented by varying procedures: for instance, operations for carpal tunnel release, cruciate ligament repair, inguinal hernia repair and prostate hyperplasia. Participant demographics are presented in Table 1. The interviews were conducted on the patients' 14th30th postoperative day to ensure that they had experienced recovery but still had their perceptions clear in their mind. Due to their practical circumstances, three patients were interviewed on postoperative days 11,32 and 37 , respectively. 
Table 1. Demographics of participants $(n=31)$

\begin{tabular}{ll}
\hline Gender & 23 \\
Male & 8 \\
Female & \\
Age & 1 \\
$<20$ years & 25 \\
$20-69$ years & 5 \\
$\geq 70$ years & \\
Residence & 23 \\
Cohabitating & 8 \\
Single & \\
Living area & 21 \\
Urban & 10 \\
Rural & \\
Education & 12 \\
Compulsory school & 13 \\
Secondary school & 5 \\
Degree from university & 1 \\
Missing & \\
Employment & 13 \\
Hired/entrepreneur & 5 \\
Student & 12 \\
Retired & 1 \\
Unemployed & \\
Type of surgery & 9 \\
Orthopaedic & \\
General & \\
Urologic &
\end{tabular}

\section{Data collection}

Three pilot interviews were carried out to test the questions in relation to the study aim and procedure. Since the questions and procedure seemed valid, no changes were made and the pilot interviews were included in the analysis. All interviews were conducted by the first author over a seven-month period (June-December 2011). The interviews were held at the patients' homes, and ranged from 16 to 49 minutes. All interviews were initiated with a broad question regarding the patient's perception of postoperative recovery: What does recovery after a day surgical procedure mean to you? The interviewer used a semi-structured interview guide complemented with follow-up and probe questions to stimulate the respondent in 
answering. For clarification, the interviewer often summarized the answer: By that, do you mean...? The interviews were audio-recorded and transcribed in Swedish using transcription conventions in a broad transcription format, capturing pauses and listener support items (Linell, 1994). Transcription was performed by a professional with extensive experience of research interview transcription. The transcriptions were compared and validated against the audio-recordings. Excerpts presented in the results section have been translated into English.

\section{Data analysis}

To find and define the descriptive categories expressed in the interviews, the analysis work followed the iterative procedure described by Dahlgren and Fallsberg (1991). Initially, the interviews were listened to and read carefully to achieve familiarity with the content. The most significant statements of perceived recovery were selected and compared to find their variations. Similar statements were grouped together and described in categories. The resulting categories were denoted with suitable and descriptive labels and, finally, the categories were compared and contrasted. No strict boundaries between the various steps exist, meaning that the analysis goes back and forth. The first author performed the analysis, with continuous support from the co-authors. NVivo 9 (QSR International Pty Ltd, Doncaster, Australia), a qualitative research software program designed to help users organize and analyse non-numerical data, was used in the analysis work.

\section{Ethical considerations}

Preoperative anxiety is common, and a patient is in a vulnerable state upon admission to a surgery unit, which can have had an impact on the decision regarding study participation. The character of the interview questions was not judged to be uncomfortable or incommodious, but answering personal questions might affect a patient's personal integrity. To reduce these 
concerns, the patients were informed about the nature and objective of the study. To make them comfortable with the decision regarding study participation, the voluntariness of participation, the possibility to withdraw from the study at any stage, the patient's protection in the findings, and contact information for the researchers were emphasized both written and verbally. Before the interview commenced, consent was signed. Confidentiality was maintained through the use of coded transcriptions. Data were only available to the authors, and were stored safely otherwise. The study was approved by a regional ethical review board (study code 2011/86-31), and was conducted in accordance with the Declaration of Helsinki (2008).

\section{Results}

Three descriptive categories emerged: 'Conditions for recovery at home', made up of factors that influenced the recovery period; 'The rollback to ordinary life', describing postoperative recovery and its consequences on daily living; and 'Being a cog in a flow of care', which represented the efficiency and structure perceived in the day surgery context and its effect on recovery. Excerpts from the interviews have been used to describe the results.

\section{Conditions for recovery at home}

In the interviews, several conditions for managing postoperative recovery at home emerged. These conditions included preparation for surgery as well as readiness to act on postoperative self-care needs. Patients' knowledge and personal traits mattered in the recovery process, and their sense of security was affected. The patients had these conditions in common, but related to them in various ways. These contrasts are illustrated in Table 2. 


\section{Preparing oneself for surgery}

To facilitate recovery, the patients prepared themselves to greater or lesser degrees. Some made a great deal of preparations and obtained knowledge about the procedure from books, magazines and the Internet, and consulted experienced people within their personal sphere. To be able to focus on the recovery period, practical preparations were also undertaken. This included completing or postponing tasks in their private or professional life. Preparation for medical issues included securing the expected supply of analgetics, bandages and company at home for the day of discharge. Emotional preparation focused on the intention of the surgery and its consequences post-discharge. Other patients did not prepare themselves at all. Reasons for this could include enthusiasm for a long-awaited procedure, expected pain relief or simply the assumption that a day surgical procedure ought to be minor and should not require preparation.

\section{The impact of personal traits during the recovery process}

A positive mood and an optimistic attitude about the surgery outcome, along with confidence in the situation, were perceived as benefitting the recovery process. Some stubbornness was useful; things might be complex and time-consuming, but the patient had to cope with them. Experience from previous day surgical procedures or structured physical training were also assumed to facilitate recovery. Motivational and fatalistic approaches were two different strategies for handling recovery. The motivational approach was expressed in a very clear and desired goal picture, while the fatalistic approach implied that the patient was just carried along the recovery trajectory. 


\section{Useful knowledge for managing recovery}

Relating to what passes for normal biologic recovery was difficult. Patients desired directions for safe ways to deal with the tissue trauma caused by the surgery, as well as an indication of normal recovery time for their particular surgery. Also, thoughts about adequate medication bothered the patients. Chiefly, these thoughts concerned type of medication and intake intervals. Wound management and its hygiene aspects were difficult. The proceedings of the surgery and anaesthesia were unclear, and patients wanted to be more informed about this. To establish reasonable expectations concerning recovery when they were discharged, patients sought realistic and truthful information. However, a more general approach to useful knowledge was also expressed, implying that simply understanding an uncomplicated recovery process was enough.

\section{Individual strategies for the post-discharge management of self-care}

Self-care entailed the body, the wound and everyday issues. Signals from the body, for instance symptoms intensity, were used as directions when deciding on relevant self-care actions. Also, common sense regarding the body was trusted when managing self-care. Recommendations from the caregiver, for instance the schedule for analgetics and the training programme, were supportive. Bodily self-care meant looking after oneself, eating, drinking and exercising properly. Wound care was a substantial part of the self-care: the patient had to change dressings, assess healing and intervene if needed. Self-care also included practical solutions for everyday issues, for instance personal hygiene, food intake and indoor ambulation. Further, self-care did not imply any particular interventions. Informal, ordinal training was a natural part of everyday life. Self-care was handled independently as long as possible, and was supported by health care only in exceptional cases. Vitamin intake, massage and household remedies were complements in self-care. 
Sense of security post-discharge

The impact of surgery on patients' feelings of security was significant. The most inner border of physical integrity had been passed, and in combination with the rapid care at the surgery unit, feelings of insecurity arose at home. Patients were doubtful about the recovery progression, which raised speculation concerning normality and relevant expectations, and made them worried and lonely. Moreover, if a patient was dependent on care received from primary health care and this care was vague regarding accessibility and structure, feelings of insecurity arose. Being insufficiently prepared for home discharge also raised feelings of insecurity; however, the confirmation of easy access to the health care provider by telephone relieved these feelings. A personal network including people with medical knowledge enhanced feeling of security at home. 
Table 2. Contrasting excerpts and subcategories included in the main descriptive category, Conditions for recovery at home

\begin{tabular}{|c|c|c|}
\hline Illustration of contrasting excerpts & Subcategories & $\begin{array}{l}\text { Main descriptive } \\
\text { category }(1 / 3)\end{array}$ \\
\hline $\begin{array}{l}\text { "I don't wake up after an operation and feel } \\
\text { like... what do I do now? I'd done everything } \\
\text { before" (Patient (Pt) 20). } \\
\text { "Since it was supposed to be a simple } \\
\text { operation I didn't look up anything special } \\
\text { about it" (Pt 19). }\end{array}$ & $\begin{array}{l}\text { Preparing oneself for } \\
\text { surgery }\end{array}$ & \multirow{5}{*}{$\begin{array}{l}\text { Conditions for } \\
\text { recovery at home }\end{array}$} \\
\hline $\begin{array}{l}\text { "You have to trust yourself the whole time that I } \\
\text { can do this" (Pt 7). } \\
\text { "I guess I'm a bit of a fatalist, I exercise and then } \\
\text { whatever happens happens" (Pt 1). }\end{array}$ & $\begin{array}{l}\text { The impact of personal } \\
\text { traits during the } \\
\text { recovery process }\end{array}$ & \\
\hline $\begin{array}{l}\text { "Answers to these questions would've } \\
\text { helped me a lot. What can I do, when can I } \\
\text { do it?" (Pt 5). } \\
\text { "I had the knowledge in that I understood } \\
\text { that I had to make sure the recovery worked" } \\
\text { (Pt 26). }\end{array}$ & $\begin{array}{l}\text { Useful knowledge for } \\
\text { managing recovery }\end{array}$ & \\
\hline $\begin{array}{l}\text { "It's just common sense for me. Because } \\
\text { what else do you have to go by? Then it's } \\
\text { really just to feel your own signals" (Pt 2). } \\
\text { "I don't need to go to the gym and things } \\
\text { like that, because I get it automatically here } \\
\text { at home" (Pt 17). }\end{array}$ & $\begin{array}{l}\text { Individual strategies } \\
\text { for the post-discharge } \\
\text { management of self- } \\
\text { care }\end{array}$ & \\
\hline $\begin{array}{l}\text { "You don't have anybody to talk to. You'd } \\
\text { so like to talk to somebody and ask if it's } \\
\text { natural to feel this poorly" (Pt 14). } \\
\text { "I have an advantage in that I have someone } \\
\text { who's knowledgeable about medicine here at } \\
\text { home. I guess I have extra security there' (Pt } \\
\text { 13). }\end{array}$ & $\begin{array}{l}\text { Sense of security post- } \\
\text { discharge }\end{array}$ & \\
\hline
\end{tabular}




\section{The rollback to ordinary life}

Being recovered implied a return to one's ordinary life and habits. Before this was accomplished, the patients described different experienced characteristics of recovery. Various physical and emotional consequences following surgery were also experienced, which involved varying sources of support (Table 3).

\section{Perceived characteristics of recovery}

On the postoperative trajectory, bodily signs were instinctively analysed and the level of activity adjusted to these references. Pain, unexpected swelling and soreness were common postoperative symptoms, and for patients who had undergone surgery in the prostate or bladder, bleeding and urinary tract infections were very problematic. Initially the need for rest was obvious, followed by a gradual increase in energy and an ability to take part in social life. This gradual improvement was parallel with a feeling of biological healing. It was assumed that recovery would be rapid and uncomplicated, and dysphoria and grumpiness could arise when it did not follow this path. The recovery period could even be seen as a bracket in life to put aside and forget; pain, a dearth in social contacts, inactivity and tiredness were reasons for this.

\section{The impact of physical restrictions during recovery}

Due to physical restrictions, several adjustments were necessary for handling ordinary life following surgery. Personal hygiene was complicated when one hand/arm was not able to be used or was bandaged. Common housekeeping was difficult and a shift in the usual roles in the family could be necessary, with an increased workload on the partner. A dependency on external people for housekeeping and transportation was noted, as was a restriction to stay in the home environment due to unfit shoes and clothes and an inability to take care of one's 
personal appearance. Spare-time physical activities, with their relaxing impact on life, were missing. On the other hand, when the surgical procedure meant that physical activities a patient had long not been able to perform were again feasible, satisfaction was expressed.

\section{Experienced emotional consequences following surgery}

The emotional impact of the surgery was surprising. Patients wanted comfort and to be cuddled at home, since the surgery and anaesthesia made them tired. When the recovery and surgical outcome did not go as expected, this provoked anxiety regarding work ability, the future and even parenthood. Being sick-listed raised feelings of no longer being useful, and having well planned and structured days at home was seen as a positive way to prevent these feelings. On the other hand, recovery and sick leave were also a welcome break in everyday life. The patient's energy was restored, and there was time to contemplate things and slow down in life.

\section{Need of support in ordinary life}

Both practical and emotional support was requested. Practical support consisted mainly of ordinary indoor tasks such as housekeeping and cooking, and also related to the patient's health; mostly to wound management. This type of support was found in the family, but also within the personal network. When the patient was self-employed, the family was not a sufficient source of support and regular substitutes were needed to run the business. Further, valuable emotional support was received from family and friends, but external sources were also used; for instance, receiving positive feedback when visiting the physio- or occupational therapist during rehabilitation was considered helpful. 
Table 3. Contrasting excerpts and subcategories included in the second main descriptive category, The rollback to ordinary life

\begin{tabular}{|c|c|c|}
\hline Illustration of contrasting excerpts & Subcategories & $\begin{array}{l}\text { Main descriptive } \\
\text { category }(2 / 3)\end{array}$ \\
\hline $\begin{array}{l}\text { "I could say, but this swelling, it's irritated } \\
\text { me more than I expected" (Pt 15). } \\
\text { "I just thought my knee would be good, like } \\
\text { it was before I hurt it. That was my belief } \\
\text { about the recovery" (Pt 2). }\end{array}$ & $\begin{array}{l}\text { Perceived } \\
\text { characteristics of } \\
\text { recovery }\end{array}$ & \multirow{4}{*}{$\begin{array}{l}\text { The rollback to } \\
\text { ordinary life }\end{array}$} \\
\hline $\begin{array}{l}\text { "I haven't been able to do much of what I } \\
\text { usually do...instead it's the wife who's been } \\
\text { more burdened" (Pt } 3 \text { ). } \\
\text { "Before surgery I didn't have much to } \\
\text { occupy myself with. But now I've started } \\
\text { digging in the garden again" (Pt 16). }\end{array}$ & $\begin{array}{l}\text { The impact of physical } \\
\text { restrictions during } \\
\text { recovery }\end{array}$ & \\
\hline $\begin{array}{l}\text { "It's in your head the whole time that it } \\
\text { [won't turn out well]... You want to be with } \\
\text { them, help them [the children]. It's things } \\
\text { like that. To be a good dad" (Pt 19). } \\
\text { "It wasn't just nice to have this operation. I } \\
\text { got a bit of calm in my life. I got a break } \\
\text { from this and that, and it's been unbelievably } \\
\text { helpful" (Pt 27). }\end{array}$ & $\begin{array}{l}\text { Experienced emotional } \\
\text { consequences } \\
\text { following surgery }\end{array}$ & \\
\hline $\begin{array}{l}\text { "I've needed help with routine stuff. Things } \\
\text { you don't think about otherwise" (Pt 5). } \\
\text { "You feel like you get positive feedback } \\
\text { [from the physiotherapist] and you feel like } \\
\text { it's moving the recovery forward" (Pt 27). }\end{array}$ & $\begin{array}{l}\text { Need of support in } \\
\text { ordinary life }\end{array}$ & \\
\hline
\end{tabular}




\section{Being a cog in a flow of care}

The experience of being a patient in day surgery was twofold. On the one hand, the effectiveness and the standardized procedures felt safe; on the other hand, it was objectifying. Some patients were excluded from decisions regarding their own health, and the interlocutor's position in perioperative communication was elucidated. A heavy responsibility was experienced regarding recovery and surgical outcome after discharge.

\section{Experiences from being a participant in effectiveness}

Patients experienced both advantages and disadvantages of an effective and structured day surgery organization. Some patients felt like objects - exemplified as cars on a conveyor belt or a parcel sent here and there - and exceptions to organizational rules were unusual. Others experienced stress because of an organization with tight time schedules; this experience of stress made them feel they were being "kicked out" of the surgery unit. This posed a risk that they would forget to discuss essential postoperative issues at discharge. With reduced time in connection to discharge, a feeling of abandonment was experienced when entering the recovery process, especially as some lacked planned contact with the health care system. Most desired was a return visit to the surgeon, but a telephone call would also do. When contacted, the patients wanted to have their actual health status confirmed and an opportunity to discuss the progression of their recovery and specific postoperative issues. On the other hand, despite high speed and efficient manners among the staff, satisfaction was expressed. The staff acted nice, were competent and worked in a closely united team, which in turn made the patients feel safe and in focus. However, upon discharge they were left to their own devices, which was distressing and was not made better by the fact that they would now be in a familiar environment at home and resting in their own bed. 


\section{To be involved or not in health decisions}

A wish to be involved in health decisions regarding themselves was apparent, and when this did not occur patients felt excluded and marginalized. The reason for this originated mostly from the fact that the patients did not know why a specific decision had been made. In some cases they had to face a changed medical condition, and in other cases their own competence or past history was not considered. On the other hand, gratitude was experienced when a decision was made in negotiation with the patient.

\section{Experiences of the interlocutor's position in perioperative communication}

Under optimal circumstances the patients were informed in advance about the surgical procedure and postoperative issues, but this was not always the case. It happened that information was given while the patient was lying on the operation trolley waiting for the anaesthesia to start. Postoperative information was provided in connection with discharge, while several patients were experiencing the lingering effects of anaesthesia and as a consequence were drowsy and did not remember what was said. Information could be given swiftly and was sometimes contradictory, with one caregiver giving one recommendation and another recommending something quite the opposite. These disparate recommendations left patients confused. Above all, they desired clear recommendations regarding physical activity since they were afraid of negatively affecting the surgical result by doing something wrong. Information in this area was experienced as vague. Patients received information from different sources; if they had contact with physio- or occupational therapists, these were regarded as valuable sources of information. Others regarded family and friends as the most valuable contributors of information to the perioperative situation. Patients were confident that they could get in touch with the surgery unit when needed, which for some compensated for forgotten or insufficient information. Moreover, patients were confident that if they did 
not reach the surgery unit, other instances in the public health system would be available to give postoperative advice or care.

\section{The burden of postoperative responsibility}

Post-discharge, patients felt that the responsibility for preventing complications and for the surgery outcome rested on them. Before undertaking things in ordinary life, they carefully analysed them using a fine-tuned ear to listen inward to their own body. Other patients experienced that managing the increased responsibility implied taking the postoperative process seriously, being focused on it and having the courage to ask questions if they were insecure. Strong self-confidence was beneficial for preventing feelings of loneliness and insecurity. Patients had to handle medical issues on their own, and the assessment of physical symptoms, for instance pain and bleeding, was worrisome. Adherence to the self-care advice they had received was regarded as important, and in cases of adherence failure some patients took responsibility for this themselves. 
Table 4. Contrasting excerpts and subcategories included in the third main descriptive category, Being a cog in a flow of care

\begin{tabular}{|c|c|c|}
\hline Illustration of contrasting excerpts & Subcategories & $\begin{array}{l}\text { Main descriptive } \\
\text { category }(3 / 3)\end{array}$ \\
\hline $\begin{array}{l}\text { "But I mean it's this conveyor belt principle. } \\
\text { They don't have time to talk to the patient in } \\
\text { a calm atmosphere, to explain etc..." (Pt 14). } \\
\text { "They were very calm and confident in what } \\
\text { they did. And everybody did what they were } \\
\text { supposed to, safely and in a calm way" (Pt } \\
\text { 6). }\end{array}$ & $\begin{array}{l}\text { Experiences from } \\
\text { being a participant in } \\
\text { effectiveness }\end{array}$ & \multirow{4}{*}{$\begin{array}{l}\text { Being a cog in a } \\
\text { flow of care }\end{array}$} \\
\hline $\begin{array}{l}\text { "One of the nurses came and said 'we're } \\
\text { going to insert a permanent urine catheter in } \\
\text { you.' I didn't have a choice" (Pt 30). } \\
\text { "After two weeks of my being sick-listed it } \\
\text { was still bleeding, so I needed to be sick- } \\
\text { listed longer. I rang up and asked and we } \\
\text { agreed on one more week. It was no } \\
\text { problem" (Pt 29). }\end{array}$ & $\begin{array}{l}\text { To be involved or not } \\
\text { in health decisions }\end{array}$ & \\
\hline $\begin{array}{l}\text { "It's really hard to get a ton of information } \\
\text { when you've just woken up. It's not really } \\
\text { that you're super smart just then and } \\
\text { remember...or actually are even interested in } \\
\text { what somebody wants to say to you" (Pt 5). } \\
\text { "I rang them yesterday. I have some stitches } \\
\text { that are still there, which I didn't know if } \\
\text { they were supposed to be or not" (Pt 10). }\end{array}$ & $\begin{array}{l}\text { Experiences of } \\
\text { perioperative } \\
\text { communication }\end{array}$ & \\
\hline $\begin{array}{l}\text { "It feels like it's totally dependent on me. I } \\
\text { mean it feels like I myself am supposed to } \\
\text { consider things so that the healing process } \\
\text { goes as it should" (Pt 2). } \\
\text { "But if you don't follow what you've gotten } \\
\text { from them [instructions], you're responsible } \\
\text { for what happens" (Pt 25). }\end{array}$ & $\begin{array}{l}\text { The burden of } \\
\text { postoperative } \\
\text { responsibility }\end{array}$ & \\
\hline
\end{tabular}




\section{Discussion}

From a phenomenographic perspective, this study aimed to explore day surgery patients' different experiences of postoperative recovery. Three categories emerged, elucidating the varying perceptions of recovery post-discharge.

Day surgery patients must take an active part in preoperative preparations at home (Gilmartin, 2004). In this study, preoperative preparations varied from an extensive search for knowledge in qualified sources and the use of modern technology, to no preparation at all. Day surgery patients have previously been described as not being very keen on seeking preoperative information (Leino-Kilpi et al., 2009), which might be due to a prevailing misconception that same-day surgery equals same-day recovery. There is a risk that non-realistic perspectives on the recovery trajectory will induce the burden on patient and family regarding recovery commitment. Various models of interprofessional work are feasible for assessing and informing the patient preoperatively (Lewis et al., 2009) and thereby also strengthening the potential for a successful postoperative period. It is possible that psychological factors matter when approaching day surgery, but these are rarely investigated in this context (Nilsson et al., 2009, Tsapakis et al., 2009). However, in the current sample personal traits contributed to how patients dealt with recovery at home. This is in accordance with our earlier study among orthopaedic day surgical patients (Berg et al., 2011), which found that emotional status on the first postoperative day is a significant predictor of recovery.

A prominent finding in this study was patients' lack of knowledge about the recovery process; they lacked the confidence to judge whether or not their progression was 'normal'. In everyday life, normality is the typical, the average and the desired (Hoedemaekers and ten Have, 1999). Patients in the current sample searched for normality regarding their health in 
their postoperative situation, a situation that was not familiar to them. They had questions about the expected content of recovery regarding their specific surgery when trying to evaluate the normality of their progression. It is stipulated that normality represents what is familiar, habitual, common and found frequently or in accordance with what can be expected, i.e. usualness (Hoedemaekers and ten Have, 1999). In this view of the normal, the current patients desired more tailored instructions; they wanted information on what to expect in a common range of recovery regarding their specific surgical procedure. Commonly, day surgery patients receive information in the biophysiological and functional domains of knowledge (Leino-Kilpi et al., 2009). Despite this, the current patients had concerns regarding postoperative pain, wound management, personal hygiene, level of exercise and return to work. These areas were already reported by Bradshaw et al. in 1999 as being inadequately explained (Bradshaw et al., 1999). Not much appears to have changed over the years, and there still seems to be space for improved knowledge and understanding in these areas.

Self-care is a paramount part of postoperative recovery at home, and patients constantly assess bodily symptoms and signs to intervene properly and to take relevant measures to solve everyday problems. Self-care is multi-faceted and the literature regarding the concept is extensive, focusing mostly on chronic illness. In this context, self-care refers to involvement in promoting health through the augmentation of internal and external resources and the prevention of adverse sequelae (Riegel et al., 2012). The core of self-care is the performance of daily routine behaviours and making healthy decisions based on the patient's current status (Dickson and Riegel, 2009), aiming to promote or maintain health (Richard and Shea, 2011, Riegel and Dickson, 2008). These perspectives might, at least on a general level, be possible to transfer to day surgery. Symptom recognition, knowledge and skills in self-care performance, as well as confidence in the situation, are essential in successfully managing 
self-care (Riegel and Dickson, 2008). Autonomy is vital in deliberate self-care; in day surgery, it may be seen as a self-governing ability in the patient's control of self-care during recovery (Aveyard, 2000). Successful self-care develops over time, as valuable skills are based on perceived experiences (Dickson and Riegel, 2009, Thorne and Paterson, 2001). To manage self-care and prevent patients from having to make mistakes in order to learn, education in the necessary skills is needed (Dickson and Riegel, 2009). These aspects of selfcare are also applicable in postoperative recovery following day surgery, with the exception that a self-care deficit following day surgery is temporary. To attain a positive outcome of postoperative recovery, it is beneficial for patients to have an early awareness regarding being well prepared for the expected self-care activities. In a day surgery context, self-care could be seen as the capability to manage symptoms and treatment as well as physical, psychosocial, cultural and spiritual consequences related to the surgical procedure (Wilkinson and Whitehead, 2009).

For the patients in our study, time savings in the organization had effects on the amount and specificity of information delivered when they were ready for home discharge, and together with the residual effects of anaesthesia, in many cases the information did not sufficiently support their recovery at home, resulting in insecurity. Boughton \& Halliday (2009) described that a lack of preparation for discharge as well as distant professionals generated a substantial degree of uncertainty in surgical patients and their families post-discharge. To facilitate health decisions at home, patients need adequate information and discharge planning. A discharge plan ought to be tailored to postsurgical needs, particularly in relation to information on recovery, and should encourage and support self-care (McMurray et al., 2007). To strengthen patients' readiness to act as autonomous performers of care at home, the discharge situation should be optimized to include a mutual assessment of whether the patient is ready for 
discharge (Renholm et al., 2009). Identified needs should be addressed (Holland and Bowles, 2012), and sufficient knowledge for the self-care confirmed (Lupien et al., 2000). Further, if the discharge plan is clearly related to the specific procedure, patient satisfaction will increase as well (Shuilain et al., 2009). During the day surgery stay, patients frequently receive new information including important details on surgical findings and postoperative issues (Blandford et al., 2011). As general anaesthesia is common in day surgery (Jakobsson et al., 2008), substantially influencing patients' ability to understand postoperative information, their management of post-discharge recovery is compromised (Blandford et al., 2011) and ought to be considered.

Trustworthiness, i.e. the extent to which the findings represent the phenomenon to which they refer, is crucial in qualitative research (Shenton, 2004). In this study the researchers were familiar with the context in which the postoperative recovery was studied, and data were collected from two day surgery units, ensuring a wide range in the selection of respondents. But indeed, it would have been interesting if some gynaecological patients had been included as well. During the interviews the interviewer clearly stated that no affiliation with the surgery unit existed, and a rephrasing and probe-question technique was used to minimize a cueseeking approach by the patients, i.e. delivering answers they assumed to be desired and correct. The processes undertaken in this study are possible to reproduce, if not necessarily to gain the same result. A tight relationship between the empirical data and the categories is seen in excerpts from the interviews, and although the results cannot be generalized (Sjöström and Dahlgren, 2002), some transferability may be achieved from this sample to other day surgery patients (Shenton, 2004). 


\section{Implications}

These results offer an insight into the situation for day surgery patients' at home. To succeed in recovery, patients need knowledge about and an understanding of the constituents of the normal range of recovery regarding their specific surgical procedure, as well as of self-care management. In contrast to the smooth and easy routines at the day surgery unit, the postoperative phase seems to be a weak link in day surgical care.

Further research on different ages may deepen the knowledge about various perceptions of recovery and its strategies. 


\section{References}

Aveyard, H., 2000. Is there a concept of autonomy that can usefully inform nursing practice? Journal of Advanced Nursing 32 (2), 352-358.

Berg, K., Idvall, E., Nilsson, U., Unosson, M., 2011. Postoperative recovery after different orthopedic day surgical procedures. International Journal of Orthopaedic and Trauma Nursing 15, 165-175.

Bettelli, G., 2009. High risk patients in day surgery. Minerva Anestesiologica 75 (5), 259-268.

Blandford, C., Gupta, B., Montgomery, J., Stocker, M., 2011. Ability of patients to retain and recall new information in the post-anaesthetic recovery period: a prospective clinical study in day surgery. Anaesthesia 66, 1088-1092.

Boughton, M., Halliday, L., 2009. Home alone: Patient and carer uncertainty surrounding discharge with continuing clinical care needs. Contemporary Nurse 33 (1), 30-40.

Bradshaw, C., Pritchett, C., Bryce, C., Coleman, S., Natress, H., 1999. Information needs of general day surgery patients. Ambulatory Surgery 7, 39-44.

Dahlgren, L., Fallsberg, M., 1991. Phenomenography as a qualitative approach in social pharmacy research. Journal of Social and Administrative Pharmacy 8 (4), 150-156.

Demir, F., Donmez, Y., Ozsaker, E., Diramali, A., 2008. Patients' lived experiences of excisional beast biopsy: a phenomenological study. Journal of Clinical Nursing 17, 744751.

Dickson, V., Riegel, B., 2009. Are we teaching what patients need to know? Building skills in heart failure self-care. Heart \& Lung 38 (3), 253-261.

Gilmartin, J., 2007. Contemporary day surgery: patients' experience of discharge and recovery. Journal of Clinical Nursing 16 (6), 1109-1117.

Gilmartin, J., 2004. Day surgery: patients' perceptions on a nurse-led preadmission clinic. Journal of Clinical Nursing 13, 243-250.

Hoedemaekers, R., ten Have, H., 1999. The concept of abnormality in medical genetics. Theoretical Medicine and Bioethics 20, 537-561.

Holland, D., Bowles, K., 2012. Standardized discharge planning assessment. Impact on patient outcomes. Journal of Nursing Care Quality 27 (3), 200-208.

Horvath, K., 2003. Postoperative recovery at home after ambulatory gynecologic laparoscopic surgery. Journal of Perianesthesia Nursing 18 (5), 324-334.

Jakobsson, J., Warrén Stomberg, M., Rawal, N., Brattwall, M., Segerdahl, M., 2008. Day surgery for knee arthroscopy, open hernia repair and laparoscopic cholecystectomy anaesthetic routine and practice: The results from Swedish nationwide survey. Ambulatory Surgery 14 (2), 42-48.

Kleinbeck, S., 2000. Self-reported at-home postoperative recovery. Research in Nursing \& Health 23, 461-472.

Leino-Kilpi, H., Heikkinen, K., Hiltunen, A., Johansson, K., Kaljonen, A., Virtanen, H., Salanterä, S., 2009. Preferences for information and behavioral control among adult ambulatory surgical patients. Applied Nursing Research 22, 101-106.

Lemos, P., Pinto, A., Morais, G., Pereira, J., Loureiro, R., Teixeira, S., Nunes, C., 2009. Patient satisfaction following day surgery. Journal of Clinical Anesthesia 21 (3), 200-205.

Lewis, S., Stocker, M., Houghton, K., Montgomery, J., 2009. A patient survey to determine how day surgery patients would like preoperative assessment to be conducted. The Journal of One Day Surgery 19 (2), 32-36.

Linell, P., 1994. Transkription av tal och samtal: teori och praktik (Trancriptions of talks and conversations: theory and practice). Tema kommunikation, Linköping University, Sweden (in Swedish). 
Lupien, A., Schonebom, B., Wren, K., 2000. Limitations to self-care in the ambulatory surgical patient. Journal of Perianesthesia Nursing 15 (2), 102-107.

Majholm, B., Esbensen, B., Thomsen, T., Engbaek, J., Möller, A., 2012. Partner's experiences of the postdischarge period after day surgery - a qualitative study. Journal of Clinical Nursing 21 (17-18), 2518-2527.

Martin, A., Nunez, R., Andrews, J., Martin, G., Andrews, P., Castle, E., 2010. Outpatient prostatectomy: too much too soon or just what the patient ordered. Urology 75, 421-426.

Marton, F., 1981. Phenomenography - describing conceptions of the world around us. Instructional Science 10, 177-200.

Marton, F., Booth, S., 1997. Learning and Awareness. Lawrence Erlbaum Associates Publishers, New Jersey.

Mattila, K., Toivonen, J., Janhunen, L., Rosenberg, P., Hynynen, L., 2005. Postdischarge symptoms after ambulatory surgery: first week incidence, intensity, and risk factors. Anesthesia and Analgesia 101, 1643-1650.

McMurray, A., Johnson, P., Wallis, M., Patterson, E., Griffiths, S., 2007. General surgical patients' perspectives of the adequacy and appropriateness of discharge planning to facilitate health decision-making at home. Journal of Clinical Nursing 16, 1602-1609.

Mitchell, M., 2003. Impact of discharge from day surgery on patients and carers. Brittish Journal of Nursing 12 (3), 402-407.

Mitchell, M., 2010. A patient-centred approach to day surgery nursing. Nursing Standard 24 (44), 40-46.

Mottram, A., 2012. Day surgery patient's perceptions of risk: a qualitative research study. Ambulatory Surgery 17 (4), 69-73.

Mottram, A., 2010. "Like a trip to McDonalds": A grounded theory study of patient experiences of day surgery. International Journal of Nursing Studies 48 (2), 165-174.

Mottram, A., 2011. Patients' experiences of day surgery: a Parsonian analysis. Journal of Advanced Nursing 67 (1), 140-148.

Mottram, A., 2011. 'They are marvellous with you whilst you are in but the aftercare is rubbish': a grounded theory study of patients' and their carers' experiences after discharge following day surgery. Journal of Clinical Nursing 20, 3143-3151.

Nilsson, U., Berg, K., Unosson, M., Brudin, L., Idvall, E., 2009. Relation between personality and quality of postoperative recovery in day surgery patients. European Journal of Anaesthesiology 26, 671-675.

Renholm, M., Suominen, T., Turtianen, A.-M., Leino-Kilpi, H., 2009. Continuity of care in ambulatory surgery critical pathways: the patients' perceptions. MedSurg Nursing 18 (3), 169-173.

Rhodes, L., Miles, G., Pearson, A., 2006. Patient subjective experience and satisfaction during the perioperative period in the day surgery setting: A systematic review. International Journal of Nursing Practice 12, 178-192.

Richard, A., Shea, K., 2011. Delineation of self-care and associated concepts. Journal of Nursing Scholarship 43 (3), 255-264.

Riegel, B., Dickson, V., 2008. A situation-specific theory of heart failure. Journal of Cardiovascular Nursing 23 (3), 190-196.

Riegel, B., Jaarsma, T., Strömberg, A., 2012. A middle-range theory of self-care of chronic illness. Advances in Nursing Science 35 (3), 194-204.

Rosén, H., Clabo Lauzon, L., Mårtensson, L., 2009. Symptoms following day surgery: a review of the literature. Journal of Advanced Perioperative Care 4 (1), 7-18.

Schnaider, I., Chung, F., 2006. Outcomes in day surgery. Current Opinion in Anesthesiology $19(6), 622-629$. 
Segerdahl, M., Warrén-Stomberg, M., Rawal, N., Brattwall, M., Jakobsson, J., 2007. Clinical practice and routines for day surgery in Sweden: results from a nation-wide survey. Acta Anaesthesiologica Scandinavica 52 (1), 117-124.

Shenton, A., 2004. Strategies for ensuring trustworthiness in qualitative research projects. Education for Information 22, 63-75.

Shuilain, L., Stunkel, D., Rodriguez, L., 2009. The impact of diagnosis-specific discharge instructions on patient satisfaction. Journal of Perianesthesia Nursing 24 (3), 156-162.

Sjöström, B., Dahlgren, L., 2002. Applying phenomenography in nursing research. Journal of Advanced Nursing 40 (3), 339-345.

Thorne, S., Paterson, B., 2001. Health care professional support for self-care management in chronic illness: insights from diabetes research. Patient Education and Counseling 42, 8190.

Toftgaard, C., 2012. Day surgery activities 2009. International survey on ambulatory surgery conducted 2011. Ambulatory Surgery 17 (3), 53-63.

Toftgaard, C., 2009. Day surgery development. Ambulatory Surgery 15 (1), 4-9.

Toftgaard, C., Parmentier, G., 2006. International terminology in ambulatory surgery and its worldwide practice. In: Lemos, P., Jarrett, P., Philip, B. (Eds.), Day surgery. Development and practice. IAAS, London.

Tsapakis, E., Tsiridis, E., Hunter, A., Gamie, Z., Georgakarakos, N., Thomas, P., Schizas, C., West, R., 2009. Modelling the effect of minor orthopaedic day surgery on patient mood at the early post-operative period: A prospective population-based cohort study. European Psychiatry 24, 112-118.

Tysome, J., Padgham, N., 2006. A comparative study of patient satisfaction with day case an in-patient major ear surgery. The Journal of Laryngology \& Otology 120, 670-675.

Wilkinson, A., Whitehead, L., 2009. Evolution of the concept of self-care and implications for nurses: a literature review. International Journal of Nursing Studies 46, 1143-1147.

World Medical Association Declaration of Helsinki, 2008. Ethical Principles for Medical Research Involving Human Subjects.

Wu, C., Berenholtz, S.M., Pronovost, P.J., Fleisher, L.A., 2002. Systematic review and analysis of postdischarge symptoms after outpatient surgery. Anesthesiology 96 (4), $994-$ 1003. 